\title{
The Effect of E-Learning as One of the Information Technology-Based Learning Media on Student Learning Motivation
}

\author{
Andi Widiyanto 1,*, Nugroho Agung Prabowo ${ }^{2}$, Nuryanto ${ }^{3}$, Mochammad Ircham Nashif Amarullah ${ }^{4}$, Arsyad Soni \\ Nuruzzaman ${ }^{5}$ \\ Department of Information Technology, Faculty of Engineering, Universitas Muhammadiyah Magelang, Magelang, Indonesia \\ ${ }^{1}$ andi.widiyanto@ummgl.ac.id ${ }^{*}{ }^{2}$ naprabowo@ummgl.ac.id; ${ }^{3}$ nuryanto@ummgl.ac.id; ${ }^{4}$ irchamamarullah24@gmail.com; \\ ${ }^{5}$ arsyadsoni321@gmail.com \\ * Corresponding author
}

(Received July 3, 2021 Revised August 8, 2021 Accepted August 29, 2021, Available online September 1, 2021)

\begin{abstract}
E-learning is pervasive in higher education, serving as a handy training option in today's hectic culture. Despite being a widespread phenomenon in both study and practice, e-learning is still far from being utilized successfully in any setting. This is due to a lack of study of the learners' point of view as well as insufficient thinking on the ramifications for the teachers. The first part of this research is a survey of university students' opinions and experiences with e-learning. The findings are both unexpected and expected: first, despite seeing e-learning as a promising future trend, students are still unsure of what it means and have only a limited understanding of its capabilities. Second, despite widespread adoption, there is still a sizable minority of students who have never used e-learning and are uninterested in doing so. Third, while e-learning appears to have more benefits than drawbacks, there are still many areas where it may be improved to make it truly effective. We offer some managerial implications for instructors and educational organizations based on these findings.
\end{abstract}

Keywords: Learning Media; E-Learning; Learning Motivation;

\section{Introduction}

In education, technology is being more widely used. E-learning, in particular, is pervasive in higher education $[1,2]$, serving as a tool for improving formal and informal learning effectiveness [3-6] as well as providing a practical option in a busy and demanding world. The literature contains numerous definitions of e-learning $[1,7,8]$, but here we refer to this phenomenon as "the use of the Internet and new multimedia technologies to advance the quality of learning by providing access to resources and services, as well as enabling remote exchange and collaboration" [9]. Despite its popularity, however, e-learning has yet to be properly deployed in any setting.

Despite the significant debate in academic and practitioner literature, the effective contribution of e-learning systems remains an open question, owing to the fact that most discussions have focused more on technological, financial, and administrative elements than didactic issues [10]. Even studies that focused on didactic concerns primarily looked at how instructors may use technology. With a few exceptions [10-12], the students' perspective on e-learning preparation, satisfaction, and performance is rarely discussed. Instead, now that e-learning is so widely used, studying learners is critical to creating significant advances in how we use e-learning systems. As a result, the purpose of this study is to determine whether e-learning is a real and powerful learning system for students, as well as to present some management implications and recommendations for instructors based on the learners' perspective.

The following is a breakdown of the paper's structure. First, we examine the argument over e-benefits learning's and drawbacks, as well as crucial success elements, mostly from the perspective of instructors. Second, based on the data we collected, we investigate the students' overall attitudes about e-learning, as well as the primary advantages and disadvantages they encounter in the e-learning setting. Finally, we provide some management implications for instructors to consider when it comes to effective design and usage of e-learning systems. 


\section{Literature Review}

Information and communications technology are quickly evolving and are now pretty much pervasive in our professional and personal life. Consequently, the use of technology for educational purposes is evolving as well, and e-learning represents one of its most relevant applications [4]. Despite their use, e-learning however remains underutilized [13] particularly if we take into account its potentialities. The real effectiveness of e-learning systems and how to make them really widespread are therefore still under debate. The adoption of e-learning in education, especially for higher educational institutions has several benefits. E-learning is considered among the best methods of education and has motivated universities to invest their resources on implementing Web-based or online courses. Many studies and authors have provided benefits derived from the adoption of e-learning technologies into schools [14]. These benefits are in particular flexibility, interactivity and efficiency: e-learning can be done at any time, at any place and from anyone; it frees instructors and learners from physical interaction constraints; it is more affordable and it can save time and money $[15,16]$. Ensuring the realisation of these benefits is a way to ensure e-learning effectiveness as well [17].

Instead, the high cost of technology and the lack of a strategy $[18,19]$ together with a lack of ability to stimulate active interaction within the e-learning course [20] are the main ones driving ineffectiveness. In general research has proved that understanding these factors is essential to improve e-learning utilization, satisfaction and performance [21]. Starting from them, research has theorized factors affecting the successful implementation of e-learning. For example, Wu et al. [22] identified the learners' cognitive beliefs (self-efficacy and performance expectations), the technological environment (system functionality and content feature), and the social environment (interaction and learning climate); while Basak et al. [16] suggested an even more omni-comprehensive model, including technological, institutional, pedagogical, management, ethical, evaluation, resources, social interaction factors.

However, despite the importance of knowing how all of these variables interact in the learner's experience from his or her own perspective, these models have primarily been designed and tested from the instructors' perspective. There are only a few recent studies in the literature that look into how students perceive e-learning, such as comparing students' preferences and self-assessment of learning for onsite, online, and hybrid delivery methods [23], revealing students' readiness [24], and implementation issues with regard to e-learning [12], and looking into the factors that affect online performance in collaborative settings.

Despite these efforts, educational institutions need more research to develop successful strategies, such as course delivery, effectiveness, and acceptance [15]. In fact, offering any conceivable course and attempting to replicate the classroom is not the solution; it will almost certainly fail to meet the students' expectations. As a result, the purpose of this research is to look into the following three concerns in order to provide instructors and educational institutions with information about how they might employ e-learning:

- The overall perception of e-learning among university students, both in terms of what they mean by it and its future developments.

- Students' e-learning experiences, including how often they use it, why they use it, and how satisfied they are with it.

- Students comprehend the benefits and drawbacks of e-learning platforms.

\section{Research Methods}

The empirical study was done among university students in 2015, with a total of 277 individuals responding to an online questionnaire. The questionnaire asked about the personal experience of e-learning, its future developments, pros and disadvantages using both multiple choice and Likert scale questions. The following is a description of the sample. Between the ages of 19 and 30, 56.4 \% are female and $43.6 \%$ are male. When compared to the age range immediately preceding, the distribution of students in the women sub-sample follows general data in a more consistent way, whereas the male sample has a significant concentration of students aged 28 to 30, and a higher presence of students older than 34. (between 31 and 33 years old).

In terms of nationality, the sample is primarily made up of Italian students $(88.99 \%)$, with Spanish (3.52\%), French $(2.20 \%)$, and Russian students accounting for the remainder $(2.20 \%)$. Other nationalities made up $3.08 \%$. A Graduate course is attended by $39.65 \%$ of the students in the sample, followed by a Master's Degree program by $21.15 \%$. The remainder of the sample is distributed as follows: $18.94 \%$ enroll in undergraduate studies courses, $15.42 \%$ in other courses, and $4.85 \%$ in a Ph.D. program. Engineering (14.54\%), Humanities (13.66\%), Social Sciences (11.89\%), Science (9.69\%), and others are the most common disciplines studied (42.73\%). 7.49\% Internal 
A. Widianto et al / IJIIS vol. 4, no. 2, September 2021, pp 123-129

consistency was used to evaluate the scales' psychometric qualities. Cronbach's alpha for each construct exceeds 0.65 , indicating that the constructs are internally consistent.

\section{Results and Discussion}

\subsection{Students Opinions Towards E-learning, Today and in the Future}

The first set of questions looked into the students' self-awareness of the significance and trends of e-learning. E-learning, according to $45.81 \%$ of student, consists of using electronic equipment to learn (including content delivery via electronic media such as the internet, audio, video, satellite broadcast, interactive TV, CD-ROM...). $30.84 \%$ believe it is a combination of processes targeted at knowledge acquisition and application, with knowledge being mostly delivered through electronic devices that rely on networks and computers. Finally, $23.35 \%$ identify e-learning as a technology that transforms the Internet into a participatory platform in which users not only consume knowledge (through download), but actively contribute to and continue with new content (via uploading).

This demonstrates that there is still a lack of consensus on an e-learning definition, implying that, despite its widespread use, e-learning requires more clarity. In terms of the future use of e-learning, the evidence indicates a good trend: 64.76 percent of students believe that e-learning will continue to expand in importance in the future, with favorable effects. On the other hand, $17.62 \%$ of students believe that e-learning will not expand and may even shrink in the coming years, while a comparable amount believes that it will not undergo any substantial changes, both positive and bad. This overall favorable tendency can be traced back to the broad belief (held by $67.40 \%$ ) that e-learning technologies can help students learn and be motivated.

\subsection{Students Experience of E-learning}

A second set of questions aimed at determining how familiar the students were with e-learning. $48.02 \%$ of those polled said they had taken an e-learning course, while $21.59 \%$ said they had never taken one but would consider it in the next 24 months. The data can be interpreted in light of the disadvantages that e-learning presents, which will be described in the following section of the paper. $20.26 \%$ of the sample was not interested in any e-learning course, and this data can be interpreted in light of the disadvantages that e-learning presents, which will be described in the following part of the paper (Table 1).

Students were also asked to report on their happiness with e-learning as part of the study. Overall, e-learning is seen as a viable and effective method of training delivery. The classes were rated as satisfactory by half of the participants. Overall, $86 \%$ of the sample would like to take another e-learning course in the future and would recommend the same experience to others (Table 2). Furthermore, the poll reveals that the majority of respondents $(84.40 \%)$ believe they have learned everything they require. However, just $47 \%$ of those who learned something shared what they had learned with their classmates. This could indicate that e-learning is more focused on individual learning than on social learning. When it comes to how students utilize e-learning systems, they describe them as primarily an online platform where they may download and share resources. More than $55 \%$ of students agree to using e-learning as a tool for sharing and downloading information. This shows that people's understanding and awareness of e-learning technologies is fairly restricted. Students undervalue the ability to use e-learning tools to study concepts, complete self-assessments, and engage with other students and instructors outside of the classroom's physical limits.

Table. 1. Student answer percentage about question "Have you ever attended an e-learning course?"
Yes, in the last 12 month
$35.68 \%$
Yes, in the last 24 month
$6.17 \%$
Yes, not in the recent past
$6.17 \%$
No, but I'm willing to attend one in the next 12 months
$6.17 \%$
No, but I'm willing to attend one in the next 24 months
$3.96 \%$
No, but I would like to do it in the future
$21.59 \%$ 
A. Widianto et al / IJIIS vol. 4, no. 2, September 2021, pp 123-129

No, and I'm not interested in

$20.26 \%$

Table. 2. Student rate satisfaction about e-learning courses

\begin{tabular}{lc}
\hline Strongly satisfied & $10.09 \%$ \\
Satisfied & $40.37 \%$ \\
Neutral & $35.78 \%$ \\
Dissatisfied & $11.93 \%$ \\
Strongly dissatisfied & $1.83 \%$ \\
\hline
\end{tabular}

Table. 3. Perceived advantages of e-learning (more than one answer is possible)

Increasing flexibility (time and place)

Sharing of teaching materials

Downloading teaching materials (e.g. slides)

Updating teaching materials

Improving interaction processes with teachers

68

Getting a quick feedback

Improving collaboration and coordination among students

Improving the development of student's knowledge and skills

Fostering interaction processes among students

Total

684

\subsection{The Perceived Advantages and Disadvantages of E-learning}

Students were also asked to consider the positive and bad aspects of the e-learning system they used in the survey. The main benefits include time and space flexibility, ease and quickness in sharing material, and the ability to get material from the teacher via download (Table 3). One of the first things to notice about the drawbacks is that they are less than the benefits: 463 versus 684 . When compared to a traditional learning situation, the "reduced social interaction" is the most commonly cited negative of e-learning systems (Table 4). The results change in part based on gender and age, but no substantial differences between sub-groups were found in earlier sections.

Table. 4. Perceived disadvantages of e-learning (more than one answer is possible)

Reducing social interactions

Increasing extra costs in terms of technological equipment

Reducing the opportunity to understand the students' learning style

Facing some technological-related issues 
In terms of gender, female respondents scored higher on the following three criteria than male respondents: getting timely feedback, boosting student collaboration and coordination, and updating instructional materials. In terms of age, it's worth noting that younger students are more critical of e-learning than older students, pointing out far more problems than benefits.

\section{Conclusion}

This research helps educational institutions understand what improvements are needed in e-learning processes and systems by providing an updated overview of students' perspectives on e-learning and connecting this perspective to existing e-learning effectiveness models [16] (see Table 5). First, we believe that there is still a misunderstanding about what e-learning is, despite the fact that it is supposed to promote learning and motivation and will continue to expand as a phenomena. Due to the fact that individuals and organizations utilize e-learning for a variety of activities and e-learning is executed using a variety of technologies, Akaslan et al. [12] also reported this confusion. Instructors and organizations should invest in both technological aspects to make technology use even easier and institutional variables to bring about a cultural change in terms of learning culture in order to promote clarity [25].

Table. 5. E-Learning effectiveness models

\begin{tabular}{|c|c|c|}
\hline Areas of investigation & Main findings & $\begin{array}{l}\text { Managerial implications for } \\
\text { instructors and educational } \\
\text { organizations }\end{array}$ \\
\hline
\end{tabular}

Students opinion towards e-learning • There is confusion about a common and agreed definition of e-learning

- There is a diffused belief that e-learning is going to grow in the future

- E-learning can facilitate learning and increase motivation

Students use experience of e-learning
- E-learning is perceived as an effective option for delivering training

- E-learning seems to mainly promote individual type of learning rather than social type learning

- E-learning is mainly an online platform for sharing materials. Its potentialities are underestimated
- Foster a change in study habits and in the learning culture and ensure institutional support as well as financial one to make this change happen

- Improve the technological factors, in terms of ease of use, reliability, efficiency, but also technical support for instructors and students to facilitate a broader adoption of e-learning systems

- Change the mind-set of the learners to broaden their understanding of e-learning

- Design e-learning systems taking into account pedagogical factors, that include content analysis, audience analysis, learning strategies

- Improve the technological factors to be able to exploit all the potentialities of e-learning in terms of functionalities 
and disadvantages of e-learning than disadvantages

- The major advantages are flexibility in terms of time and space, easiness and speed in sharing material and the possibility of receiving material from the teacher via a download

- The major disadvantage is the "reduced social interaction" compared to a traditional learning context factors, creating occasions for social interaction among participants and with the instructor

- Provide tools and occasions for evaluation, developing learning assessments and allowing for easy and continuous feedback

- Ensure the right support from a management team in charge of developing contents and managing the delivery. This team should support both instructors and learners

Second, according to our research, e-learning is primarily a technology platform that allows students to download resources. This shows that students have had limited opportunities to explore the other aspects of e-learning, such as engagement and assessment. As a result, students have a limited knowledge of what they can achieve with e-learning systems and how these systems might increase their learning satisfaction and performance. This should encourage instructors to pay attention to institutional issues so that students understand how to learn and are comfortable with e-learning technologies before they use them. This could also involve bringing about and managing a shift in the learning environment. It also entails focusing on pedagogical factors in order to ensure that e-learning courses are properly designed and implemented. Instructors should consider about increasing those capabilities that are underused (e.g., those connected to social contact) and providing learning opportunities that include a larger use of e-learning possibilities as well as technological elements to assist the pedagogical ones.

According to our research, a substantial percentage of students had no prior experience with e-learning and had no desire to do so. This necessitates an investigation by educational institutions and instructors into the reasons behind this: is it a lack of curiosity, or a perception of too many drawbacks in this type of learning experience, or of too few opportunities to employ them? Instructors should work on modifying learning attitudes, making technology use easier, increasing the learning experience, or giving more diversified opportunities for use, depending on the answer. Finally, we demonstrate that while e-learning systems have a number of well-known advantages, they also have a number of drawbacks, the most significant of which is the limited connection between participants and instructors. This has important practical implications: when instructors create their e-learning program, they must take into account not just technological issues, but also social interaction characteristics, as well as management, assessment, and resource concerns. Creating opportunities for social engagement, having the proper skills and resources to manage the online content generation process, and building a feedback and assessment system are all crucial.

\section{References}

[1] Welsh, E. T., Wanberg, C. R., Brown, K. G., \& Simmering, M. J. (2003). E-learning: emerging uses, empirical results and future directions. International Journal of Training and Development, 7, 245-258.

[2] Caporarello, L., \& Sarchioni, G. (2014). E-learning: the recipe for success. Journal of e-learning and Knowledge Society, 10(1), 107-118.

[3] Wong, W. T., \& Huang, N. T. N. (2011). The effects of e-learning system service quality and users' accpetance on organizational learning. International Journal of Business and Information, 6(2), 205-225.

[4] Murillo, L. F. L., \& Velázquez, F. J. L. (2008). E-learning as a key aspect for the future of higher education. In DEXA Workshops IEEE Computer Society, 431-435.

[5] Za, S., Spagnoletti, P., \& North-Samardzic, A. (2014). Organisational learning as an emerging process: The generative role of digital tools in informal learning practices. British Journal of Educational Technology, 45(6), 1023-1035. 
A. Widianto et al / IJIIS vol. 4, no. 2, September 2021, pp 123-129

[6] North-Samardzic, A., Braccini, A. M., Spagnoletti, P., \& Za, S. (2014). Applying media synchronicity theory to distance learning in virtual worlds: A design science approach. International Journal of Innovation and Learning, 15(3), 328-346.

[7] Rosenberg, M. J. (2001). E-learning: Strategies for delivering knowledge in the digital age. New York: McGraw-Hill.

[8] Terry, L. (2000). Get smart online. Upside, 12(5), 162-164.

[9] Alptekin, S. E., \& Karsak, E. E. (2011). An integrated decision framework for evaluating and selecting e-learning products. Applied Soft Computing, 11, 2990-2998.

[10]Biasutti, M. (2011). The student experience of a collaborative e-learning university module. Computers \& Education, 57, 1865-1875.

[11] Keller, C., \& Cernerud, L. (2002). Students' perceptions of e-learning in university education. Journal of Educational Media, 27(1-2), 55-67.

[12] Akaslan, D., Law, E.L-C., \& Taskin, S. (2012). Analysis of issues for implementing e-learning: The student perspective. New York: IEEE.

[13]Lee, Y. H., Hsieh, Y. C., \& Hsu, C. N. (2011). Adding innovation diffusion theory to the technology acceptance model: Supporting employees' intentions to use e-learning systems. Educational Technology \& Society, 14(4), 124-137.

[14] McLoughlin, C. E., \& Lubna Alam, S. (2014). A case study of instructor scaffolding using Web 2.0 tools to teach social informatics. Journal of Information Systems Education, 25(2), 125.

[15]Dutta, A. K., Mosley, A., \& Akhtar, M. M. (2011). E-learning in higher education: Design and implementation. International Journal of Computer Science Issues, 8(4), 509-516.

[16] Basak, S. K., Wotto, M., \& Bélanger, P. (2016). A framework on the critical success factors of learning implementation in higher education: A review of the literature. International Journal of Social, Behavioural, Economic, Business and Industrial Engineering, 10(7), 2259-2264.

[17]Baldwin-Evans, K. (2004). Employees and eLearning: What do the end-users think? Industrial and Commercial Training, 36(7), 269-274.

[18]Elloumi, F. (2004). Value chain analysis: A strategic approach to online learning. In A. Anderson \& F. Elloumi (Eds.), Theory and practice of online learning (pp. 61-92). Athabasca, Canada: Athabasca University.

[19] Saadé, R. G. (2003). Web-based education information system for enhanced learning, EISL: Student assessment. Journal of Information Technology Education, 2, 267-277.

[20] Rodrigues, J. J. P. C., Sabino, F. M. R., \& Zhou, L. (2011). Enhancing e-learning experience with online social networks. IET Communications, 5(8), 1147-1154.

[21] Al-hawari, M. A., \& Mouakket, S. (2010). The influence of technology acceptance model (TAM) factors on students' e-satisfaction and e-retention within the context of UAE e-learning. Education, Business and Society: Contemporary Middle Eastern Issues, 3(4), 299-314.

[22] Wu, J.-H., Tennyson, R. D., \& Hsia, T.-L. (2010). A study of student satisfaction in a blended e-learning system environment. Computers \& Education, 55, 155-164.

[23] Castle, S. R., \& McGuire, C. J. (2010). An analysis of student self-assessment of online, blended, and face-to-face learning environments: Implications for sustainable education delivery. International Education Studies, 3(3), 36.

[24] Akaslan, D., \& Law, E.L-C. (2011). Measuring student e-learning readiness: A case about the subject of electricity in higher education institutions in Turkey. In Proceedings of the 10th International Conference on Web-Based learning. Hong Kong.

[25] Caporarello, L., \& Inesta, A. (2016). Blended learning approach: How is the learning educational paradigm changing? Reflections and a proposed framework. In F. D’Ascenzo, M. Magni, A. Lazazzara, \& S. Za (Eds.), Blurring the boundaries through digital innovation. Germany: Springer. 